\title{
E-GUIDANCE SEBAGAI INTERPRETASI YANG INFORMATIF PADA WATERWORLD TAMAN SAFARI INDONESIA
}

\author{
Ronald David M \\ Fakultas Teknologi Informasi, Universitas Merdeka Malang \\ Ronald David M
}

\begin{abstract}
Development of mapping technology to explore the benefits included in the sights with digital media. Easy access through mobile maps Gadget Internet service is required. MapInfo is an application program that is used for mapping purposes. Mapping designed this author uses MapInfo is able to provide the ability to see a map of variation, improved image quality, and the editing process on each layer. Register their facilities provide more informative map display, such as determining the distance (road and river) or wide and the scale of a region. The use in the field of tourism provides significant benefits because it can depict a variety of attractive map display related to tourism so it is easy to interpret.
\end{abstract}

Keywords : Technology, Systems, Information, Mapping

\section{PENDAHULUAN}

Sebagaimana kita ketahui bahwa dalam era globalisasi ini kemajuan teknologi sangat pesat sekali. Banyak sekali riset-riset yang dilakukan untuk mendorong timbulnya penemuan baru dalam dunia teknologi, terutama teknologi Informasi. Adapun salah satu penemuan tersebut adalah Sistem Informasi Geografis atau Geographic Information System (GIS). Dengan adanya teknologi ini maka akan memudahkan kita dalam hal pemetaan objek, dan mendapatkan berbagai macam informasi yang disajikan.

Perkembangan sistem informasi tak ada artinya tanpa didukung oleh kemajuan teknologi jaringan internet. Melalui jaringan internet memungkinkan untuk dilakukannya komunikasi, interaksi, bahkan transaksi antar data yang secara fisik terpisah.

Teknologi ini mengatasi semua hambatan baik dimensi waktu maupun dimensi ruang selama tempat tersebut masih terhubung dengan perangkat dan jaringan Internet.

Sehubungan dengan perkembangan sistem informasi dan kemajuan teknologi jaringan internet tersebut, perlu diupayakan semaksimal mungkin termasuk di bidang pariwisata, sehingga dapat mendukung maksimalnya pemasukan negara dalam industri pariwisata.

\section{Tujuan}

Rancangan Sistem Informasi Geografis (GIS) dalam bidang pariwisata yang dihasilkan diharapkan mampu menjadi salah satu alternatif pengembangan sistem industri pariwisata di Indonesia.

\section{Rumusan Masalah}

Bagaimana Sistem Informasi Geografis (GIS) dengan interprestasi yang informatif dan dapat diaplikasikan dalam bidang pariwisata dalam tulisan ini Obyek wisata Waterworld Taman Safari Prigen sebagai sampel obyek wisata.

\section{Sistem Informasi Geografis (GIS)}

Sebelum pembahasan tentang pengertian Sistem Informasi Geografis sebaiknya kita memahami dulu apa yang dimaksud dengan sistem informasi. Sistem informasi merupakan kesatuan elemen yang tersebar dan saling berinteraksi yang menciptakan aliran informasi. Proses interaksi tersebut berupa proses data dengan cara pemasukan, pengolahan, integrasi, pengolahan, komputasi atau perhitungan, penyimpanan, serta distribusi data atau informasi.

Perlu dibedakan antara data dan informasi. Data merupakan fakta yang ada dan melekat pada suatu obyek seperti nilai, ukuran, berat, luas, dan sebagainya. Sedangkan informasi merupakan pengetahuan tambahan yang diperoleh setelah dilakukan pemrosesan dari data tersebut. Nilai suatu informasi amat bergantung dari pengetahuan yang dimiliki oleh pengguna.

Dengan kata lain informasi merupakan sekumpulan data yang relevan dan berkaitan (sesuai dengan tingkatan validitas dan 
reliabilitasnya), yang diolah dan diproses menjadi bentuk yang mudah dipahami, disukai, dan mudah diakses. Pengguna bebas memanfaatkan informasi sebagai pengetahuan, dasar perencanaan, landasan pengambilan keputusan, sampai kepada hal yang sederhana seperti hiburan.

Sistem informasi terdiri dari Non Spatial Information System dan Spatial Information System (SIS). Sedangkan SIS terbagi dua menjadi Non Resorce SIS dan Resource SIS. Kemudian Resource SIS terbagi dua lagi, yaitu Geographical Information System (GIS) dan Land Information System (LIS).

Geographical Information System (GIS) atau Sistem Informasi Berbasis Pemetaan dan Geografi adalah sebuah alat bantu manajemen berupa informasi berbantuan komputer yang berkait erat dengan sistem pemetaan dan analisis terhadap segala sesuatu serta peristiwa-peristiwa yang terjadi di muka bumi.

Teknologi GIS (GIS) mengintegrasikan operasi pengolahan data berbasis database yang biasa digunakan saat ini, seperti pengambilan data berdasarkan kebutuhan, serta analisis statistik dengan menggunakan visualisasi yang khas serta berbagai keuntungan yang mampu ditawarkan melalui analisis geografis melalui gambar-gambar petanya.

GIS lebih dikenal sebagai software tools: perangkat lunak, antara lain seperti: ArcInfo, MapInfo, AutoCadMap, Grass, dan masih banyak lagi. Dengan tools yang sama maka GIS berkaitan dengan proses dan presentasi peta-peta skala kecil (peta LandUse, Kehutanan), sedangkan LIS berkaitan dengan peta-peta skala besar, yaitu peta bidang-bidang tanah (land parcels).

\section{Manfaat Aplikasi Sistem Informasi Geografis (GIS)}

GIS adalah sebuah aplikasi dinamis yang memungkinkan sebuah peta yang dibuat pada aplikasi ini tidak hanya akan berhenti dan terbatas untuk keperluan saat dibuat saja, tetapi bisa dikembangkan. Peremajaan terhadap informasi yang terkait pada peta tersebut secara otomatis akan menunjukkan setiap perubahan. GIS memudahkan pemberian penjelasan tentang suatu peristiwa, membuat peramalan kejadian, dan perencanaan strategis lainnya.

Teknologi GIS memungkinkan untuk menunjukkan informasi bisnis pariwisata secara keseluruhan dengan cara pandang baru melalui basis pemetaan dan relationship.

Para pelaku bisnis yang bergerak di bidang pemasaran, periklanan, real estate, dan ritel menggunakan GIS untuk melakukan analisa pasar, mengoptimalkan kampanye periklanan melalui media masa, analisis terhadap bidangbidang tanah, dan membuat model atas pola pengeluaran.

Keuntungan utama GIS adalah kemampuan mengindentifikasi hubungan spasial diantara feature data geografis dalam bentuk peta. GIS tidak hanya sekedar menyimpan peta menurut pengertian konvensional yang ada dan tidak pula sekedar menyimpan citra atau pandangan dari area geografi tertentu. Akan tetapi, dapat menyimpan data menurut kebutuhan yang diinginkan dan menggambarkan kembali. GIS menghubungkan data spasial dengan informasi geografi tentang feature tertentu pada peta. Informasi ini disimpan sebagai atribut atau karakteristik dari feature yang disajikan secara grafik.

Sebagai contoh, jaringan jalan dapat disajikan dengan jalur tengah jalan (road centerlines), pada keadaan ini, representasi visual yang sebenarnya dari jalan tidak akan memberikan terlalu banyak informasi tentang jalan tersebut. Untuk memperoleh informasi tentang jalan, misalnya lebar atau jenis jalan, kita dapat menanyakan ke database, kemudian menentukanan simbol tampilan jalan menurut jenis informasi yang perlu ditampilkan.

GIS dapat juga menggunakan atribut yang tersimpan untuk menghitung informasi baru mengenai feature peta sebagai contoh, untuk menghitung panjang jalan tertentu atau mendeterminasi luas total dari jenis tanah tertentu.

GIS juga dapat dijelaskan dengan dua cara :

1. Melalui definisi format data

2. Operasi spasial, menghubungkan kumpulan data dengan menghubungkan lokasi sebagai kunci umum.

Penginputan data yang paling banyak dilakukan yang berkaitan dengan data geografi adalah datacitra satelit. Data ini berbentuk raster atau grid. Data seperti ini dapat diproses melalui analisa dengan menggunakan perangkat lunak yang disebut sistem pemprosesan citra (Image Processing System). Data dapat juga diinput dengan memasukkan data vektor yang ada di 
bumi, yaitu dengan meng-gunakan alat yang dinamakan digitizer.

Data disimpan di database. Database GIS berbeda dengan database sistem drafting biasa dimana dengan sistem drafting biasa, outputnya hanya berbentuk grafik sedangkan database GIS dapat menggabungkan data textual dengan data grafik.

\section{METODE PENELITIAN}

Penelitian ini dilakukan dengan langkahlangkah berikut:

1. Pengumpulan Data

Data yang digunakan dalam tulisan ini adalah peta primer dan peta sekunder Guide Map waterworld Taman Safari.

2. Metode Studi

Metode studi yang digunakan adalah studi literature. Penulis melakukan studi literatur melalui buku dan internet berhubungan dengan tema yang diambil.

3. Penyusunan Data

Penulis menyusun struktur sistem dan mengisi data sampel

4. Analisa Data

Penulis menganalisa data hasil dari inputan untuk mengetahui kesalahan-kesalahan data yang terjadi sebelum dilakukan pengolahan informasi lebih lanjut

\section{HASIL DAN PEMBAHASAN}

Jenis data yang digunakan adalah data primer dan data sekunder. Data primer diperoleh berdasarkan pada pendekatan geografis (pengambilan gambar peta Waterworld Taman Safari) seperti tampak pada gambar 1 Data sekunder diperoleh berdasarkan hasil survey dan pencarian informasi lain melalui media elektronik.

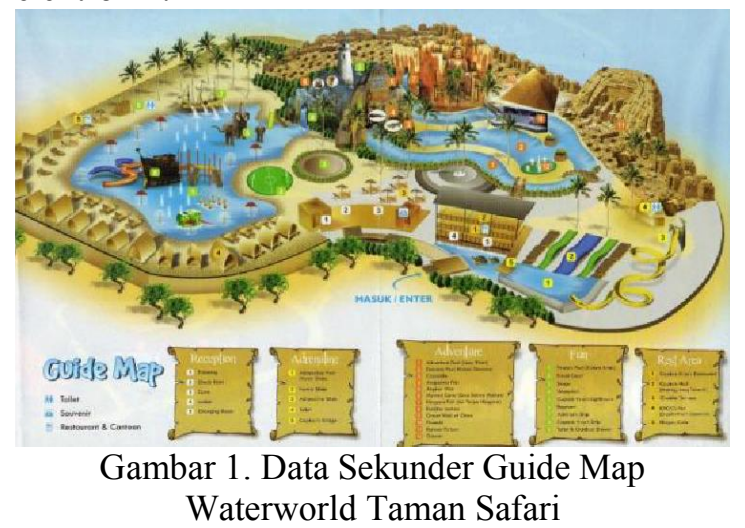

\section{Pre - Processing}

Pre-processing adalah proses awal mengelola data sebelum pengolahan data yang dilakukan pada sistem GIS. Proses ini bertujuan agar data yang ada dapat dipakai pada proses di dalam GIS, dalam hal ini pada software MapInfo.

\section{Kondisi Awal Data}

Data primer ini adalah peta waterworld taman safari dengan format .jpg, maka harus dikonversi ke dalam software MapInfo menjadi format tab.

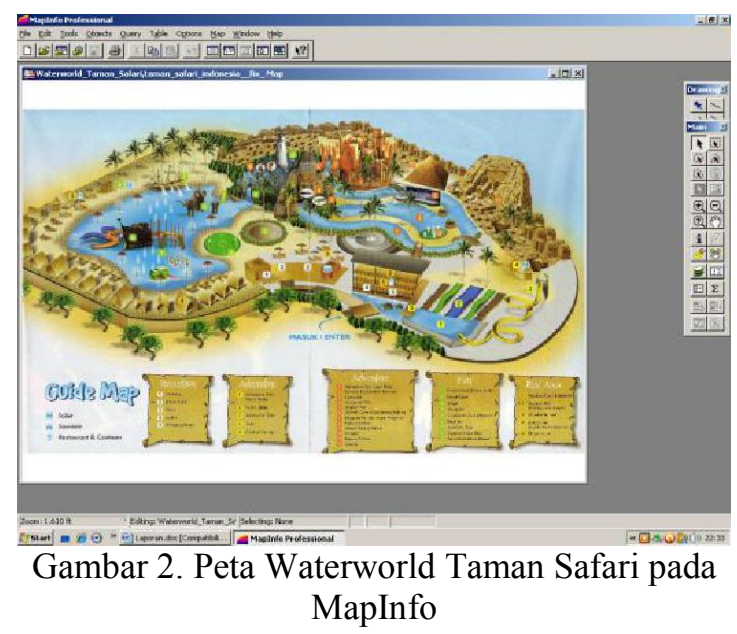

Proses yang dilakukan pada data awal ini adalah proses pengeditan untuk keperluan sistem lebih lanjut adapun diagram alir dari proses pengeditan data spasial adalah sebagai berikut :

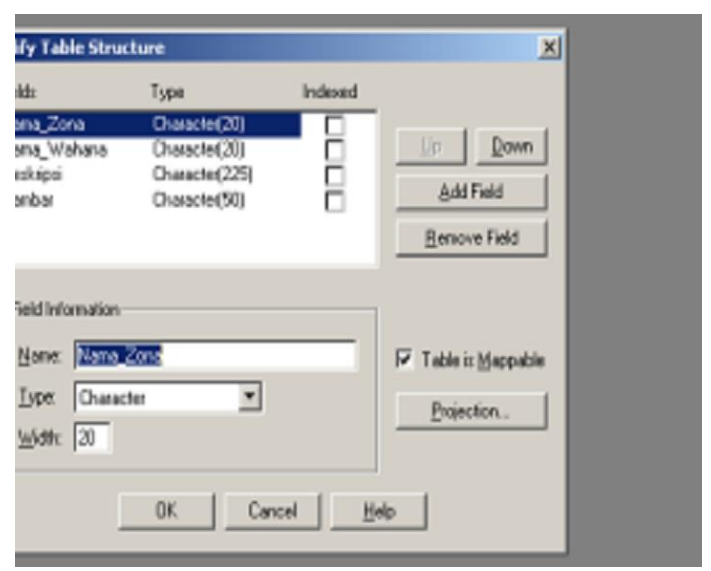

Gambar 3. Layer - layer pada MapInfo 


\section{ISSN: 1693-6604}

Struktur tabel yang akan dibentuk adalah sebagai berikut:

1. Struktur Tabel Zona_Waterworld

2. Struktur Tabel Wahana_Waterworld

3. Struktur Tabel Deskripsi

4. Struktur Tabel Gambar

Proses selanjutnya adalah buat Struktur Tabel dengan cara memilah gambar pada peta waterworld taman safari yang bisa digunakan sebagai HotLink seperti berikut ini:

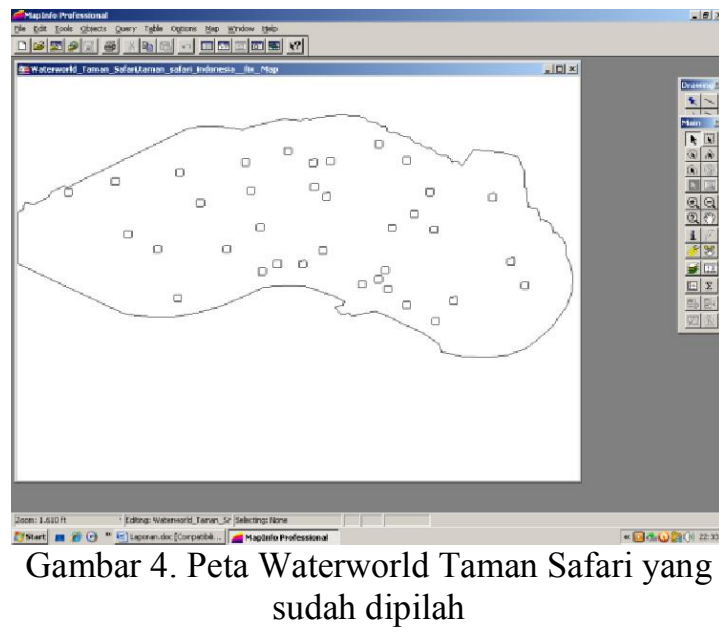

Proses pengisian Tabel Zona Waterworld, Tabel Wahana Waterworld, dan Tabel Deskripsi dapat diisikan pada tabel yang sudah disediakan di dalam MapInfo, seperti berikut ini:

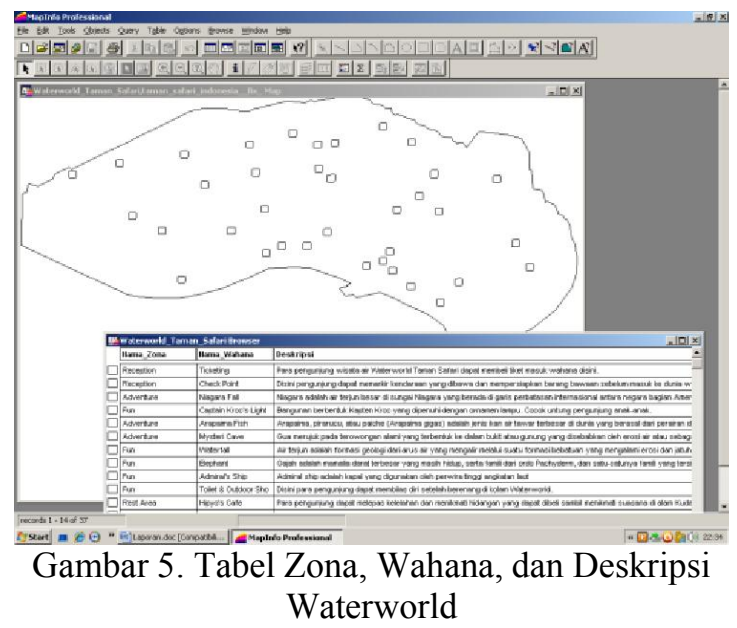

Selanjutnya memasukkan HotLink dengan cara mengetikkan alamat folder gambar yang ingin dimasukkan ke dalam tabel "Gambar" seperti berikut ini:

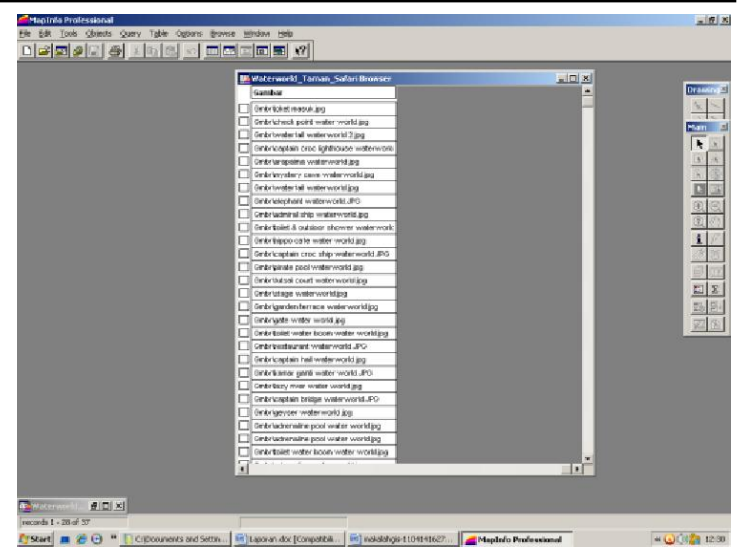

Gambar 6. Pengisian HotLink pada tabel "Gambar"

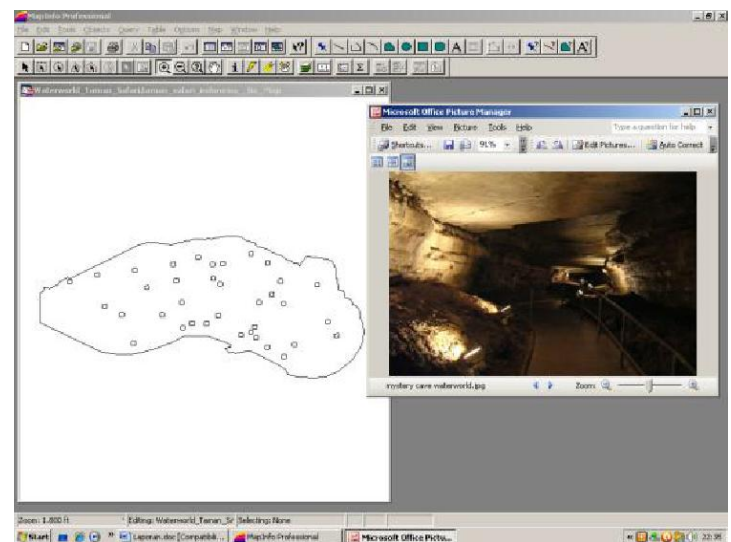

Gambar 7. Tampilan Gambar yang sudah memakai HotLink

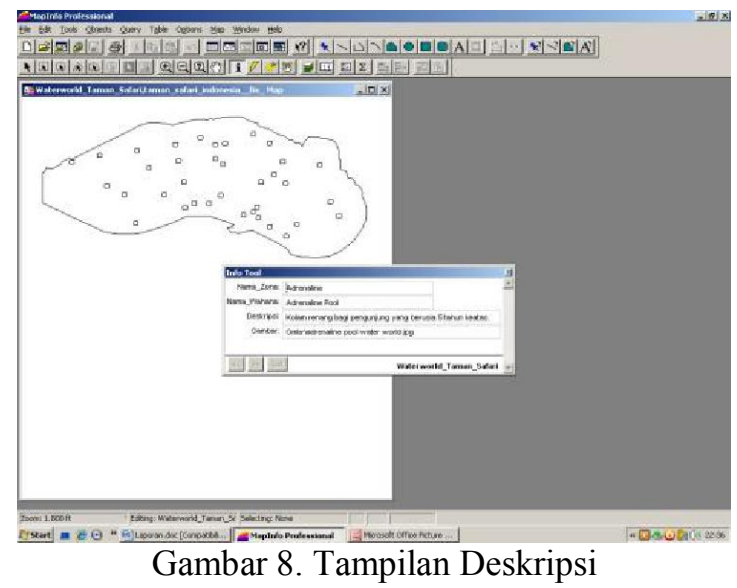

\section{KESIMPULAN}

Sistem Informasi geografis sebagai alternatif implementasi sistem pariwisata yang menyajikan informasi disertai data yang lengkap tentang kondisi suatu daerah. Perancangan sistem Informasi yang dapat diakses secara mobile akan 
memudahkan pencapaian kepuasan pada pengunjung.

Pengembangan sistem yang bisa

dioperasikan melalui Gadget multiplatform sangat disarankan sehingga GIS pariwisata waterworld taman safari bisa diakses secara mobile.

\section{REFERENSI}

[1] Wikipedia.Sistem Informasi Geografis. 3 Juni 2006

[2] Deny Carter, Irma Agrigasari, "Desain dan Aplikasi GIS", Elexmedia, Jakarta, 2004

[3] Budiyanto, Eko, "Sistem Informasi Geografis menggunakan MapInfo", Andi, Yogyakarta, 2004

[4] Charter, Denny, "MapInfo Professional", Informatika, Bandung, 2004

[5] Prahasta, Eddy. "Konsep - Konsep Dasar Sistem Informasi Geografis", Informatika, Bandung, 2001. 